free-responding procedures. It may be pointed out that the TO reduced overall reinforcement rate. In the present study, both increasing the ratio size and decreasing the reinforcement duration involved reducing the amount of reinforcement per unit of time. Any manipulation which reduces the overall amount of reinforcement per unit of time may produce similar results. Such an interpretation implies that performance would be faster when the reinforcement rate is increased by removing the TO. However, Fig. 1 reveals that in the FR 60/no-TO phase, a general decrease in start speeds and ratio rates was observed rather than the increase predicted by the reinforcement rate interpretation.

While other explanations are possible for the finding that a discrete-trials procedure was more sensitive to reinforcement duration than a free-responding one, there are little data upon which to make an objective choice. More research is needed to test some of the possible alternative explanations.

\section{REFERENCES}

Bitgood, S. C., \& Platt, J. R. A discrete-trials PREE in an operant situation. Psychonomic Science, 1971, 23, 17-19.

Brown, P. L., \& Jenkins, H. M. A utoshaping of the pigeon's key-peck. Journal of the Experimental Analysis of Behavior, $1968,11,1-8$.

Capaldi, E. J., \& Lynch, D. Repeated shifts in reward magnitude: Evidence in favor of an associational and absolute (contextual) interpretation. Journal of Experimental Psychology, 1967, 75, 226-235.

Felton, M., \& Lyon, D. O. The post-reinforcement pause. Journal of the Experimental Analysis of Behavior, 1966, 9 , 131-134.

Ferster, C. B., \& Skinner, B. F. Schedules of reinforcement. New York: Appleton-Century-Crofts, 1957.

Platt, J. R. Discrete-trials and their relation to free-behavior situations. In J. T. Spence \& H. H. Kendler (Eds.), Essays in neobehaviorism: $A$ memorial to Kenneth $W$. Spence. New York: Appleton-Century-Crofts, 1971.

Powell, $R$. W. The effect of small sequential changes in fixed-ratio size upon the post-reinforcement pause. Journal of the Experimental Analysis of Behavior, 1968, 11, 589-593.

Powell, $R$. W. The effect of reinforcement magnitude upon responding under fixed-ratio schedules. Journal of the Experimental Analysis of Behavior, 1969, 12, 605-608.

Powell, $R$. W. Probability of reinforcement and fixed-ratio responding: A model. Psychological Record, 1970, 20, 73-80.

Schwartz, B. Effects of reinforcement magnitude of pigeons preference for different fixed-ratio schedules of reinforcement. Journal of the Experimental Analysis of Behavior, 1969, 12, 253-259.

Senkowski, P. C. Temporal course of motivational after-effects of reward and nonreward. Unpublished Doctoral Dissertation, University of Iowa, 1970.

Staddon, J. E. R. Temporal effects of reinforcement: A negative "frustration" effect. Learning \& Motivation, 1970, 1 , 227-247.

(Received for publication March 21, 1973.)

\title{
Negative contrast in goldfish (Carassius auratus)*
}

\section{THERESE L. COCHRANE, STANLEY R. SCOBIE and DANIEL FALLON \\ State University of New York at Binghamton \\ Binghamton, N.Y. 13901}

Goldfish in a successive differential discrimination displayed strong negative contrast. A successive nondifferential shift in reward magnitude did not produce clear negative contrast, however. Response speed changed appropriately when reward magnitudes were changed. There was no indication of positive contrast in either condition.

Much work on contrasted conditions of reward has been done with rats as Ss, but work with goldfish (Bitterman, 1969; Lowes \& Bitterman, 1967; Mackintosh, 1971; Raymond, Aderman, \& Wolach, 1972) has failed to

*This is a preliminary report of aspects of research to be subsequently reported in greater detail. The research was supported by MH 19961 from the National Institute of Mental Health. demonstrate either positive or negative contrast. These "negative" findings were partly responsible for Bitterman's (1969) description of fish as animals primarily responsive to laws governing simple stimulus-response bonds. The demonstration of contrast in goldfish would seem to imply behavior which is not readily accounted for in terms of simple stimulus-response bonds, and would be of substantial theoretical interest.

One criterion we can use to classify successive "contrast effects" differentiates situations in which the organism has the opportunity to compare different reward magnitudes directly, within a daily trial sequence, from situations in which reward magnitudes are experienced in separate successive blocks in time (Dunham, 1968). The first case, successive differential contrast, typically involves intermixed trials, signaled by different stimuli and resulting in different magnitudes of reward. Rats in such a situation usually display negative contrast, responding more slowly on small reward trials than do animals given the same small reward presented alone, 


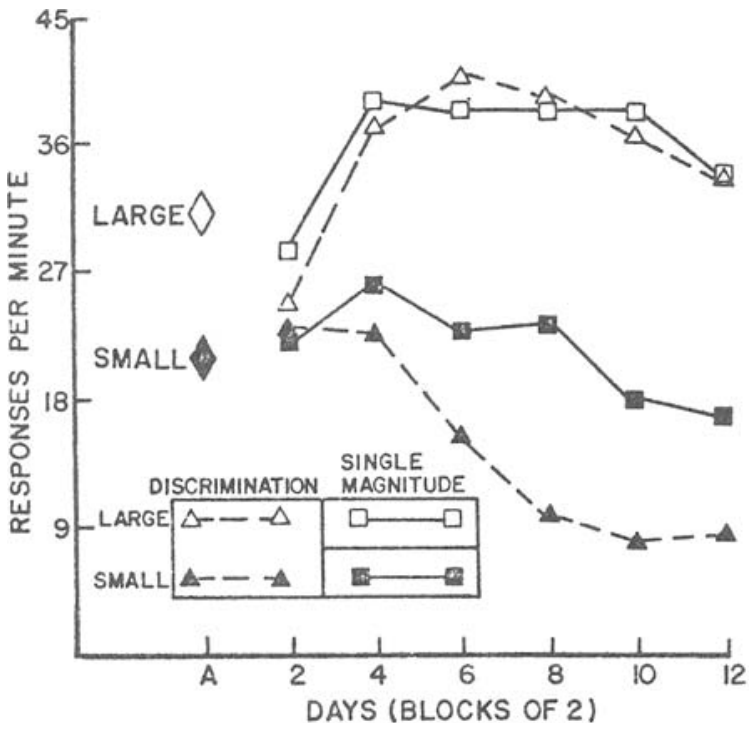

Fig. 1. Mean response rates to large and small reward for each of two single-magnitude groups $(\mathrm{N}=6)$ and one discrimination group $(N=12)$. The data for the discrimination group have been combined from the two separate discrimination groups, L-D and S-D, that did not differ from each other (see text). The leftmost points are rates under large and small reward on the final 2 days of original acquisition.

without other reward magnitudes interspersed (e.g., Bower, 1961). Positive contrast in the successive differential situation would be seen as faster responding on trials signaling large when small-reward trials are interspersed than in a large-reward-only control condition (see Dunham, 1968). The second situation, the successive nondifferential case, has been reported to result in slower runway performance relative to a nonshifted control condition, when animals are shifted from a large reward to a small reward, and faster runway performance when animals are shifted from a small to a large reward (e.g., Crespi, 1942). The effect displayed by upshifted animals is called positive contrast; that displayed by downshifted animals is called negative contrast.

The experiments that failed to find negative contrast in goldfish all used a successive nondifferential paradigm and varied widely in task and reinforcement variables. All found differential performance based on reward magnitude used initially in training; i.e., large reward resulted in faster performance. However, only the work of Raymond et al (1972) showed a substantial shift in level of responding when reward magnitude was shifted from large to small. In the other studies, either no change occurred or the change was not statistically reliable. Negative contrast did not appear; in fact, the necessary condition for negative contrast, a change in level of performance when reward magnitude is changed from large to small, did not occur. These results, taken together, seem to suggest that the mechanisms relating reward magnitude to performance in fish are quite different from those in mammals. However, the Raymond et al (1972) finding does show that at least one of the necessary conditions for demonstrating negative contrast, downward shift in level of performance, can be obtained with fish. This at least suggests the possibility that unidentified variables may have masked the occurrence of contrast.

In preliminary work in our laboratory (Cochrane, Fallon, \& Scobie, 1972), we found a reliable negative contrast effect in goldfish using the successive differential paradigm; fish responded more slowly to a color associated with small reward within a large-small discrimination than did a small-reward-only control group. However, our data were rather variable, and we did not demonstrate clearly a large-reward/small-reward performance difference in groups trained with just single reward magnitudes.

We were encouraged by this work and felt that as yet unidentified aspects of our procedure might allow demonstration of both successive differential and nondifferential contrast effects. Although we did not find positive contrast in our earlier work, we thought that refinements in our laboratory which had resulted in decreased variability might allow us to obtain this result also. Note, however, that positive contrast is usually not obtained within these paradigms (e.g., Bower, 1961; Dunham, 1968; but see, e.g., Mackintosh, Little, \& Lord, 1972).

To allow an evaluation of both differential and nondifferential shifts in reward, we trained six groups of fish by factorially combining two levels of reward, large and small, and three levels of reward shift: no shift, successive nondifferential shift, and successive differential shift. Half our Ss were trained to respond for large reward and half for small. Then all animals were shifted to one of three conditions: a control condition where the same reward magnitude remained in effect; a nondifferential shift condition in which animals were switched to the opposite magnitude; or a differential shift condition, in which animals received interspersed large- and small-reward trials cued by different signals (discrimination training).

\section{METHOD \\ Subjects and Apparatus}

Thirty-six large goldfish (Carassius auratus) were individually housed in 8.5-liter tanks. The testing apparatus, patterned after that of Bitterman (1966), contained a nosepress manipulandum which could be transilluminated with red or green light and a separately located feeder mechanism which delivered semiliquid fish food.

\section{Procedure}

Animals were assigned randomly to six groups, three of which were shaped and pretrained to respond for a large magnitude of reinforcement, and three of which received a small magnitude of reinforcement: 0.02 and $0.002 \mathrm{ml}$, respectively (one milliliter contains $67.5 \mathrm{mg}$ of dry Tetramin fish food in a starch solution). Total food intake was equated for all Ss by extra feeding as required. Training followed a discrete trials paradigm. Animals were given 30 trials each day in an irregular sequence; half were signaled by green manipulandum illumination and half by red. The intertrial interval was $15 \mathrm{sec}$. Response to the manipulandum terminated the red or green stimulus and delivered reinforcement. Trials on which no response occurred were terminated automatically without reinforcement after $60 \mathrm{sec}$. After initial shaping with a one-response requirement, animals were required to make a fixed ratio of three responses to terminate trials. They were 
then given 30 trials per day for 14 days.

During the next phase, discrimination training, Control Groups L-L and S-S (for large to large and small to small) continued receiving either only large or only small reinforcements, respectively, on all trials. Groups L-S (large to small) and S-L (small to large) were switched to the opposite reward magnitude from that provided during the first phase. One large group and one small group (L-D and S-D) were given differential training, earning large reinforcement on all trials signaled by one color (red or green, balanced) and small reinforcement on trials signaled by the other color. Training in this phase continued for 13 days.

\section{RESULTS}

There was a clear difference in response rate (computed as: number of responses to complete a trial (3) divided by time in minutes taken to complete a trial) based on reinforcement magnitude in Phase 1 (pretraining). This is shown in the leftmost data points in Fig. 1. Animals receiving large reward responded faster than animals receiving small reward $(F=7.38, \mathrm{df}=1 / 30, \mathrm{p}<.025)$. The two groups (L-D and S-D) shifted to the reward magnitude discrimination (successive differential condition) both showed clear learning of the discrimination $(F=667.15, \mathrm{df}=1 / 10, \mathrm{p}<.001)$. An overall analysis of response speeds to small reward stimuli in the two differential groups and the two single magnitude groups (L-S and S-S) showed a significant effect of groups $(\mathrm{F}=3.72, \mathrm{df}=3 / 20, \mathrm{p}<.05)$. A planned comparison between Groups S-D and L-D and Group S-S, which received only small-reward trials, showed negative contrast in the differential groups, which responded more slowly to the small-reward stimulus than did Control Group S-S $(F=10.40, d f=1 / 20, p<.005)$. There was no indication of positive contrast, nor did original training reward magnitude influence discrimination learning. Combined data from the two discrimination groups is shown in Fig. 1, along with data from the nonshifted groups.

The outcome for the successive nondifferential shift was less clear. Fish did shift their response speeds when the reward magnitude was changed, both from small to large and, more importantly, from large to small (ps <.05). There was no difference in speed between Groups L-L and S-L and there was no statistically reliable difference between Groups S-S and L-S (Fs $<1$ ). Figure 2 shows, however, an apparent trend toward a negative contrast effect. Note that there was some drift in overall level of responding over the course of the experiment. However, all comparisons were made between appropriate groups at the same point in time.

\section{DISCUSSION}

Our findings in the differential shift paradigm are clear. Fish do show negative contrast. Positive contrast may be difficult to find because of ceiling effects, and it is often not obtained within these paradigms with other species (cf. Dunham, 1968). We did not find clear evidence for negative contrast within the nondifferential shift paradigm, but we did show a clear change in performance with a shift from large to small reward. This change is necessary for contrast to occur, and our finding of a trend toward negative contrast is consistent with similar findings by Raymond et al (1972). Thus, we think that the demonstration of negative

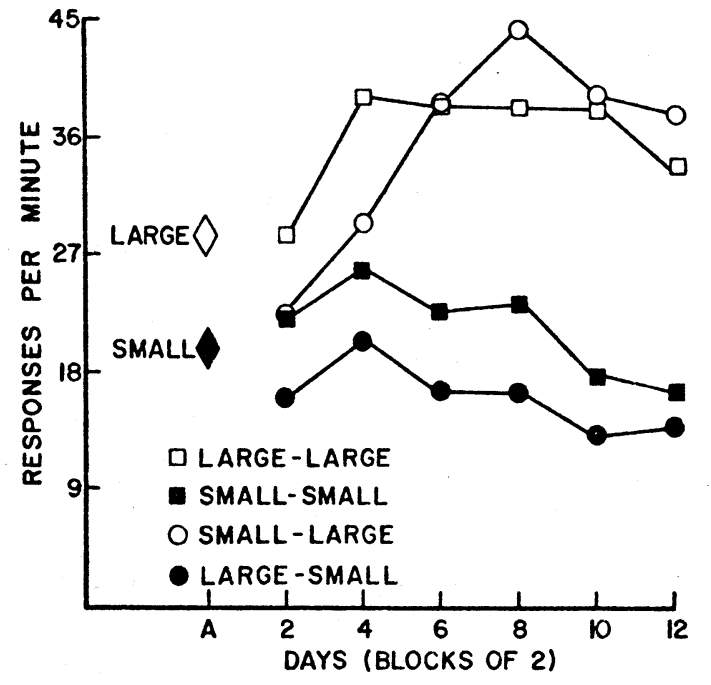

Fig. 2 Mean response rates for single-magnitude groups following reward shift. The leftmost points are rates on the last 2 days of original training.

contrast within the nondifferential shift paradigm may be possible if we can control as yet unidentified procedural variables.

One variable which distinguishes our procedure is the use of a relatively short intertrial interval. Work by others has typically used much longer intervals. Both Capaldi (1972), using rats, and Mackintosh et al (1972), using pigeons and rats, have shown that the interval between trials is related to the magnitude of contrast; contrast is weakened or destroyed by longer intervals. Work with goldfish currently in progress in our laboratory shows that successive differential negative contrast is critically dependent on the interval between trials in a very similar way.

It is much too soon to draw conclusions about differences in the specific mechanisms for contrast in rats and fish. They seem to us to be more similar than different on the basis of evidence collected thus far.

\section{REFERENCES}

Bitterman, M. E. Animal learning. In J. B. Sidowski (Ed.), Experimental methods and instrumentation in psychology. New York: McGraw-Hill, 1966.

Bitterman, M. E. Thorndike and the problem of anima intelligence. American Psychologist, 1969, 24, 444-453.

Bower, G. H. A contrast effect in differential conditioning. Journal of Experimental Psychology, 1961, 2, 196-199.

Capaldi, E. J. Successive negative contrast effect: Intertrial interval, type of shift, and four sources of generalization decrement. Journal of Experimental Psychology, 1972, 96, 433-438.

Cochrane, T.L., Fallon, D., \& Scobie, S. Negative contrast in goldfish during discrimination of reinforcement magnitude. Paper presented at the meeting of the Eastern Psychological Association, Spring 1972, Boston, Mass.

Crespi, L.P. Quantitative variation in incentive and performance in the white rat. American Journal of Psychology, 1942, 55, 467-517.

Dunham, $\dot{P}$. J. Contrasted conditions of reinforcement: A selective critique. Psychological Bulletin, 1968, 69, 295-315.

Lowes, G., \& Bitterman, M. E. Reward and learning in the goldfish. Science, 1967, 157, 455-457.

Mackintosh, N. J. Reward and aftereffects of reward in the learning of the goldfish. Journal of Comparative \& Physiological Psychology, 1971, 76, 225-232.

Mackintosh, J. J., Little, L., \& Lord, J. Some determinants of behavioral contrast in pigeons and rats. Learning \& Motivation. $1972,3,148-161$.

Raymond, B., Aderman, M., \& Wolach, A. H. Incentive shifts in the goldfish. Journal of Comparative \& Physiological Psychology, $1972,78,10-13$.

(Received for publication March 30, 1973.) 